\title{
PERJALANAN BISNIS NABI MUHAMMAD S.A.W.
}

\author{
Heriyansyah \\ Dosent Tetap Prodi Manajemen Pendidikan Islam STAI Al Hidayah Bogor \\ heristaia@gmail.com
}

\begin{abstract}
The Journey business of Prophet Muhammad Salallahu alaihi wasallam can not be separated from the Sirah Nabawiyah which is very worthy if written with gold ink, the journey of the great man of ages, the ocean of knowledge, wisdom and example of not only for his people and his companions but people his followers even bless the whole universe. One chapter of science in the course of his life is his trading journey (business), As the custom of the Arabs at that time was the Quraish tribe was the trade (business) in which he was born and raised and forged before becoming a great leader, can not be separated from the guidance of revelation Divine, since his youth has gone on a business trip with his uncle until his adulthood, this profession has become his choice, as he does the laying of honest business principles, trusts and promises. Until then he was known as Al Amin (trusted) among his people.
\end{abstract}

Keyword: journey, business

\begin{abstract}
ABSTRAK
Perjalanan bisnis Nabi Muhammad Salallahu alaihi wasallam tidaklepas dari Sirah Nabawiyah yang ditorehkan dan sangat layak jika ditulis menggunakan tinta emas, yaitu perjalanan manusia agung yang tidak lekang oleh zaman, samudra ilmu, hikmah, dan suri tauladan tidak hanya bagi kaumnya dan para sahabatnya namun umat pengikutnya bahkan umat seluruh semesta alam. Satu bab ilmu dalam perjalanan kehidupan beliau adalah perjalanan berdagang (bisnis), sebagaimana kebiasaan bangsa Arab ketika itu yaitu suku Quraisy adalah berdagang (bisnis) dimana beliau dilahirkan dan dibesarkan serta ditempa sebelum menjadi sosok pemimpin besar, tidak lepas dari bimbingan wahyu Ilahi, sejak belia beliau sudah mengikuti perjalanan bisnis dengan pamannya, sampai beliau dewasa pun profesi ini menjadi pilihannya, sebagaimana beliau melakukan peletakan prinsip-prinsip perniagaan yang jujur, amanah menepati janji dan sebagainya. Sampai beliaupun dikenal sebagai al-amin (terpercaya) di kalangan kaumnya.
\end{abstract}

\section{A. PENDAhuluan}

Segala puji bagi Allah yang maha sempurna, rabb semesta alam, yang telah mengutus rasul terakhir, penutup para nabi yang menjadi rahmat bagi alam semesta, Shalawat dan salam bagi junjungan kita, penghulu para nabi, nabi akhir zaman yaitu Nabi Muhammad Salallahu alaihi wasallam, 
beserta keluarganya dan sahabatnya serta para pengikutnya hingga akhir zaman.

Membahas tentang perjalanan bisnis Nabi Muhammad Salallahu alaihi wasallam merupakan hal yang sangat menarik untuk di kaji, tidak akan terlepas dari Sirah Nabawiyah yang merupakan samudra ilmu yang tidak akan lekang oleh kemajuan zaman dan tidak akan pernah habis untuk di ambil ibroh dan mutiara ilmu di dalamnya. Bagi siapapun yang mempelajari sejarah beliau, akan memperoleh gambaran sejarah yang amat menakjubkan, sebagaimana beliau dan para sahabatnya mampu menundukkan pesona duniawi dan mengangkat nilai-nilai kemanusiaan ke suatu tingkatan yang tidak pernah di saksikan oleh lembaga sejarah di manapun berada. Selain berupa bisnis, secara umum dilakukan melalui bekerja dan mencari penghasilan untuk memenuhi kebutuhan dan bagi keberlangsungan hidup. ${ }^{1}$

Siapapun yang mempertajam perhatiannya tentang perjalanan kisah beliau, akan terpesona kemanusiaan yang begitu indah, bagaimana beliau bisa

${ }^{1}$ Lihat Rahendra Maya. (2015). "Perspektif Islam Tentang Konsep Life Skill." Edukasi Islami: Jurnal Pendidikan Islam, 04(07). hlm. 872-873, dan menghasilkan generasi terbaiknya yang jika dicari aibnya, tentu akan sangat kesulitan mencarinya, padahal yang beliau tempa adalah manusia-manusia yang berkarakter jahiliah dan tempramen keras di wilayah gurun pasir yang tandus, di samping itu memang sebagian besar profesi mereka adalah sebagai pebisnis (berniaga/pedagang), dimana mereka sering melakukan perjalanan bisnisnya hingga keluar daerah, kota, bahkan Negara.

Dengan tulisan ini moga bisa mengambil sedikit dari samudra ilmu tentang bagai mana gambaran aktifitas perjalanan bisnis (perdagangan) yang dilakukan oleh Nabi Muhammad Salallahu alaihi wasallam yang menjadi profesi utama suku dikaumnya yaitu Suku Quraisy. Kala itu kebiasaan suku Quraisy melakukan perjalanan bisnis (perdagangan) di dua musim yaitu musim panas dan musim dingin, sebagai mana diabadaikan dalam AlQur'an Surah Al-Qurasy Ayat 1-4

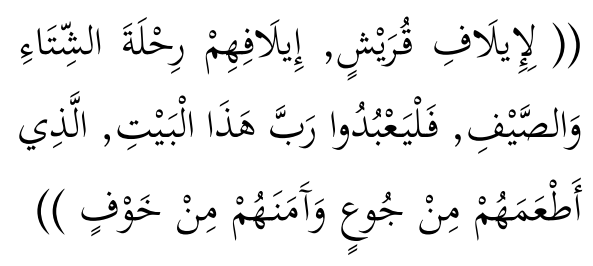

Fachri Fachrudin. (2013). "Fikih Bekerja." AlMahslahah: Jurnal Hukum Islam dan Pranata Sosial Islam, 1(01). hlm. 60-62. 
"Karena kebiasaan orang-orang

Quraisy, (yaitu) kebiasaan mereka

bepergian pada musim dingin dan

musim panas. Maka hendaklah mereka menyembah Tuhan (pemilik) rumah ini (Ka'bah), yang telah memberi makan kepada mereka untuk menghilangkan lapar dan mengamankan mereka dari rasa ketakutan." (Q.S. AlQurasy [106]: 1-4)

\section{B. PEMBAHASAN}

\section{Gambaran Kondisi Bangsa Arab}

Menurut bahasa, Arab artinya padang pasir, tanah gundul, dan gersang yang tiada air dan tanaman. Sebutan dengan istilah ini sudah diberikan sejak dahulu kepada jazirah Arab. Jazirah Arab dibatasi Laut Merah dan Gurun Sinai di sebelah barat, di sebelah timur dibatasi Teluk Arab dan sebagian besar wilayah Irak bagian selatan, disebelah utara dibatasi laut Arab yang bersambung dengan lautan India dan di sebelah utara dibatasi negeri Syam, luasnya membentang antara satu juta mil sampai satu juta tiga ratus ribu mil.
Jazirah Arab memiliki peranan yang sangat besar karena letak geografis, sedangkan dilihat dari kondisi internalnya, jazirah Arab hanya dikelilingi gurun pasir di segala sudutnya. Karena kondisi seperti inilah membuat Jazirah Arab seperti benteng pertahanan yang kokoh, yang tidak memperkenankan bangsa asing untuk menjajah, mencaplok atau menguasai bangsa Arab. Oleh karena itu, kita bisa melihat penduduk jazirah Arab yang hidup merdeka dan bebas dari segala urusan semenjak zaman dahulu. Sekalipun demikian mereka tetap hidup berdampingan dengan dua imperium yang besar saat itu yaitu Persia dan Romawi, yang serangannya tidak mungkin bisa dihalangi andaikata tidak ada benteng pertahanan yang kokoh seperti itu.

Sedangkan hubungan dengan dunia luar, jazirah Arab terletak di benua yang sudah dikenal semenjak dahulu kala, yang mempertautkan daratan dan lautan. Sebelah barat laut merupakan pintu masuk ke benua Afrika, sebelah timur merupakan pintu masuk bagi bangsa-bangsa non Arab, timur tengah, timur dekat terus membentang ke India dan Cina. Setiap benua mempertemukan lautnya dengan jazirah 
Arab dan setiap kapal laut berlayar tentu akan bersandar di ujungnya.

Karena letak geografis seperti itu, sebelah utara dan selatan dari jazirah Arab menjadi tempat berlabuh berbagai bangsa untuk saling tukar-menukar perniagaan, peradaban, agama, dan seni. ${ }^{2}$

\section{Kondisi Ekonomi Bangsa Arab}

Kondisi ekonomi mengikuti kondisi sosial yang bisa dilihat dari jalan kehidupan bangsa Arab. Perdagangan merupakan sarana paling dominan untuk memenuhi kebutuhan hidup ketika itu. Jalur-jalur perdagangan tidak sepenuhnya bisa dikuasai begitu saja, sementara itu kondisi yang aman seperti ini tidak terwujud di jazirah Arab kecuali pada bulan-bulan suci. Pada saat itu dibuka pasar-pasar Arab yang sangat terkenal, seperti pasar Ukazh, Dzil Majaz, Madinah, dan lainnya.

Mekkah, kota kelahiran dan domisili Nabi Muhammad Sallahualaihi wa sallam, termasuk tempat yang paling istimewa di jazirah Arab. Di antara keistimewaannya adalah keberadaan Ka'bah sebagai tempat ziarah orang-orang Arab dari berbagai

2 Syaikh Syafiyyurrahman Al-Mubarakfuri. (2017). Arrahiiqul Makhtum Sirah Nabawiyah. Jakarta: Pustaka Al Kautsar. hlm.2. negeri. Seiring dengan itu, kegiatan perdagangan ramai mewarnai musim ziarah di kota tersebut. Pada masa sebelum Islam, Mekkah dengan Ka'bahnya adalah pusat "ibadah" masyarakat Arab dan sekitarnya.

Tatkala Hasyim bin Abdul Manaf (kakek besar Rasulullah Salallohualaihi wa sallam) menjadi tokoh penting di Mekkah, dia berhasil membuka jalur perdagangan setahun dua kali bagi orang-orang Quraisy; ke Yaman dan Syiria. Ekspedisi dagang ke selatan (Yaman) dilakukan sewaktu musim panas, sedangkan perjalanan dagang ke utara (Syria) ditempuh pada musim dingin. Inilah yang kemudian digambarkan Al-Qur'an Surat Al-Quraisy Ayat 1-4 berikut:

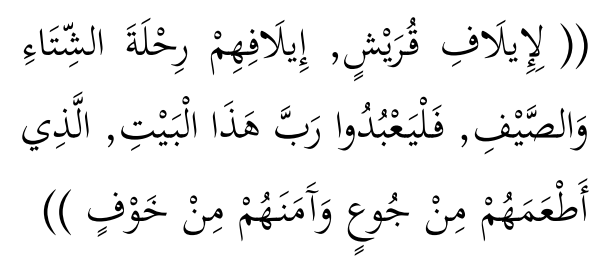

"Karena kebiasaan orang-orang Quraisy, (yaitu) kebiasaan mereka bepergian pada musim dingin dan musim panas. Maka hendaklah mereka menyembah 
Tuhan (pemilik) rumah ini (Ka'bah), yang telah memberi makan kepada mereka untuk menghilangkan lapar dan mengamankan mereka dari rasa ketakutan."

Seperti yang tertera jelas dalam Surat Quraisy di atas, secara umum bangsa Quraisy memiliki dua rute perjalanan yang didasarkan pada cuaca musim panas dan musim dingin. Perjalanan dagang musim panas dilakukan ke utara yang meliputi Syria, Yordania, Palestina, dan Lebanon. Bahkan tidak jarang, mereka melanjutkan perjalanan sampai ke Turki dan perbatasan Eropa Barat. Daerah itu menjadi favorit perjalanan kafilah dagang musim panas karena relatif lebih sejuk bila dibandingkan terik matahari Mekkah dan Jeddah. Sementara pada musim dingin, daerah selatan Mekkah seperti Yaman dan Ethiopia memiliki cuaca yang lebih hangat. Di berbagai daerah Syam bahkan turun salju. Oleh karena itu, pada musim ini bangsa Quraisy memilih berdagang ke selatan.

Dalam perkembangannya, kota Mekkah mempunyai kedudukan kian penting di seluruh jazirah Arab. Setelah kepemimpinan diteruskan Naufal dan Muttalib, Mekkah bertambah maju dan makmur. Kota Mekkah menjadi pusat transit perdagangan di jazirah Arab antara komoditas Yaman dan komoditas Syiria sehingga penduduknya lebih maju dari pada suku-suku lainnya.

Di dalam keluarga besar Muhammad Salallohualaihi wa sallam, hampir seluruh karib kerabatnya adalah pedagang. Darah pedagang dalam diri Muhammad Salallohualaihi wa sallam rupanya sudah mengalir dari kakek besar Hasym bin Abdu manaf, turun ke Abdul Muttalib sang kake, mengalir ke darah Abdullah sang ayah juga ke paman-pamannya, seperti Sayyidina Abbas dan Abu Talib. Dengan demikian juga kerabat setingkat paman seperti Abu Sufyan. Tidak ketinggalan pula sepupu dan sahabatsahabat karib beliau, seperti Ali bin abi Talib, Abu Bakr, Umar, Utsman Abdurrahman bin Auf dan Suhaib Ar-Rumi, semuanya adalah pedagang yang sangat sukses dan mandiri, dan banyak 
menciptakan lapangan pekerjaan untuk masyarakatnya. ${ }^{3}$

Kekhasan yang menyertai kegiatan dagang bangsa Quraisy kala itu, mereka menjalankan ekspedisi dagang yang terdiri dari sejumlah orang (membentuk kelompok/ kafilah), dan menjadikan unta sebagai alat tranportasi. Menurut catatan, mereka menggunakan kafilah unta yang jumlahnya bisa mencapai 1.000 hingga 2.500 ekor bersama 100 sampai 300 pengiring.

Tentang perindustrian atau kerajinan, mereka adalah bangsa yang paling mengenalnya. Kebanyakan hasil kerajinan yang ada di Jazirah Arab seperti memintal, menjahit, menyamak kulit dan lainya yang berasal dari daerah Yaman, Hirah, dan pinggiran Syam. Sekalipun begitu di tengah jazirah Arab ada pertanian dan penggembalaan hewan ternak. ${ }^{4}$

\section{Perjalanan Bisnis Pertama Nabi Muhammad S.A.W}

Selagi usia Rasulullah mencapai dua belas tahun, ada yang berpendapat lebih dua bulan sepuluh hari, paman beliau Abu Thalib yang sejak kecil dalam asuhannya mengajak beliau pergi berdagang dengan tujuan negeri

${ }^{3}$ M. Syafii Antonio. (2010). Muhammad The Super Leader Super Manger. Tazkia Publishing. hlm. 4-6.
Syam (Palestina, Syria sekitarnya sekarang), hingga tiba di Bushra, suatu daerah yang sudah termasuk negri Syam dan merupakan ibukota Hauran, yang juga merupakan ibukotanya orang-orang Arab, sekalipun di bawah kekuasaan bangsa Romawi kala itu.

Namun perjalanan beliau terhenti ketika di negeri itu ada seorang rahib yang dikenal dengan sebutan Bahira, yang nama aslinya Jurjis. Tatkala Rombongan kafilah dagang Abu Thalib singgah di daerah ini, maka sang rahib menghampiri mereka dan mempersilahkan mereka mampir ketempat tinggalnya sebagai tamu kehormatan. Padahal sebelum itu rahib tersebut tidak pernah keluar, namun begitu dia bisa mengetahui Rasulullah dari sifat-sifat beliau. Sambil memegang tangan beliau, sang rahib berkata, "Orang ini adalah pemimpin semesta alam, anak ini akan diutus Allah sebagai rahmat bagi seluruh alam."

Abu Thalib bertanya, "Darimana engkau tahu hal itu?" Rahib Bahira menjawab, "Sebenarnya sejak kalian tiba di Aqabah, tidak ada bebatuan dan pepohonan pun melainkan mereka tunduk sujud. ${ }^{4}$ Syaikh Syafiyyurrahman Al-Mubarakfuri.
hlm. 36 . 
Mereka tidak sujud melainkan kepada seorang nabi. Aku mengetahui dari stempel nubuwah yang berada di bagian bawah tulang rawan bahunya, yang menyerupai buah apel. Kami juga bisa mendapatkan tanda itu di dalam kitab kami."

Kemudian Rahib Bahira meminta agar Abu Thalib kembali lagi bersama beliau tanpa melanjutkan perjalanannya ke Syam, karena dia takut gangguan dari pihak orangorang Yahudi. Maka Abu Thalib mengirim beliau bersama beberapa pemuda agar kembali ke Makkah. $^{5}$

Sebagian sumber menceritakan, bahwa rahib itu menasihati supaya jangan terlampau dalam memasuki daerah Syam, sebab dikhawatirkan masyarakat yahudi yang mengetahui tanda-tanda itu akan berbuat jahat kepadanya. ${ }^{6}$

\section{Perjalanan Bisnis Kedua Nabi \\ Muhammad S.A.W.}

Pada awal remaja, Rasulullah tidak mempunyai pekerjaan tetap, hanya saja beberapa riwayat menyebutkan beliau biasa

${ }^{5}$ Ibnu Hisyam. (1337 H). Mukhtashar SiratirRasul. hlm.16; Sirah An-Nabawiyah. hlm 180-183., Syafiyyurrahman Al-Mubarakfuri. (2017). hlm. 54.

${ }^{6}$ Muhammad Haekal. (2011). Sejarah Hidup Muhammad. hlm. 58.

7 Al-Ghazali Muhammad. (1391 H). FiqhusSirah. Mesir: Darul KitabAl-Arabi. hlm. 52. Ar- menggembala kambing di kalangan Bani Sa'ad dan juga di Mekah dengan imbalan uang beberapa dinar. ${ }^{7}$ Dalam riwayat lain disebutkan Nabi Muhammad, sebagaimana biasanya pada masa kanak-kanak itu dia kembali ke pekerjaannya menggembala kambing; kambing keluarga dan kambing penduduk Mekah yang lain yang dipercayakan kepadanya. Pekerjaan mengembala kambing ini membuahkan didikan yang amat baik pada diri Nabi, karena pekerjaan ini memerlukan keuletan, kesabaran, dan ketenangan serta keterampilan dalam tindakan. ${ }^{8}$

Meski tidak punya pekerjaan tetap, Muhammad dikenal sebagai pemuda yang berakhlak mulia: jujur, amanah, santun, dan bersahaja. Setiap pekerjaan dilakoninya atau dilaksanakan dengan sungguh-sungguh. Kemuliaan akhlak Muhammad itu terdengar ditelinga Khadijah binti Khuwailid. Ia adalah seorang wanita pedagang yang memiliki banyak harta dan bernasab baik.

Rahiiqul Makhtum. Syafiyyurrahman AlMubarakfuri. Sirah Nabawiyah. hlm. 56.

8 Al-Qur'an dan Terjemah. Sejarah Ringkas Nabi Muhammad. Khadim al Haramain asy Syarifain Raja Fahd ibn Abd Al-Aziz Al-Sa’ud. Madinah. 
Dia banyak membayar kaum laki-laki untuk berdagang dengan sistem bagi hasil.

Khadijah pun megutus seseorang untuk mengajak Muhammad berniaga ke negri Syam. Tawaran itu diterima Muhammad, Ia bergegas berangkat menemui Khadijah. Muhammad tiba di rumah Khadijah. Muhammad mengucapkan salam dan meminta izin kepada Khadijah untuk masuk. Sebuah percakapan pun terjadi. Khadijah langsung berbicara ke inti persoalan.

"Aku sedang butuh orang untuk menjual barang daganganku ke negri Syam. Aku butuh orang yang jujur, dapat dipercaya. Aku tahu, engkau orang yang jujur dan dapat diandalkan. Aku yakin engkau adalah orang yang tepat, karenanya aku tawarkan pekerjaan ini kepadamu," kata Khadijah. Ia berjanji akan memberikan keuntungan yang lebih besar dibanding kepada saudagar lainnya.

Muhammad langsung menerima tawaran itu. Persiapan keberangkatan pun dilakukan. Khadijah meminta pelayan terbaiknya, Maisarah, sebagai asisten Muhammad. Tak lupa Khadijah membisikkan sesuatu kepada Maisarah. "Kau jangan membangkang pada Muhammad. Lakukan apa yang diinginkannya. Engkau juga harus mengamatinya sepanjang perjalanan. Ketika pulang, laporkan apa yang engkau lihat kepadaku!", bisik Khadijah.

Waktu kepergian tiba, hampir seluruh sanak saudara Muhammad berkumpul untuk melepas keberangkatannya. Perjalanan itu akan panjang, itu artinya mereka tak dapat berjumpa dengan Muhammad dalam waktu yang lama. Muhammad bersama Maisarah kemudian bertolak dalam sebuah kafilah menuju Syam, hari berganti hari, siang silih berganti dengan malam mengiringi perjalanan, Maisarah melakukan apapun agar Muhammad merasa nyaman.

Tepat pada bulan ketiga, mereka tiba di Bashra, tidak jauh dari Syam. Sebuah perayaan besar sedang berlangsung, barang dagangan digelar oleh para musafir di atas permadani.

Maisarah melihat cara berdagang yang berbeda dari kebiasaan kaum Quraisy pada umumnya, beliau dengan kejujurannya dan kefasihan dalam berkomunikasi sangat menarik simpati para pedagang yang berinteraksi dengannya. Seperti beliau dalam berbisnis tidak terlalu mengambil banyak keuntungan yang berlipat, prinsip beliau yassiru wala tuassiru yakni memudahkan 
dalam bertransaksi sehingga beliau tidak berlama-lama dalam tawar-menawar antar pedagang dan beliau tidak suka menghabiskan waktu perjalanan berniaganya (bisnis) untuk berleha-leha atau melampiaskan kesenangan-kesenangan sebagaimana umumnya kaum bangsa Arab, seperti minuman keras, berjudi, dan lainnya.

Muhammad melepas lelah di bawah pohon besar, tidak jauh dari kuil seorang rahib.

Tanpa sepengetahuan Muhammad, Nasthura, seorang pendeta, mengamati gerak-gerik Muhammad, Ia kemudian menghampiri Maisarah, "Siapa yang berteduh di bawah pohon itu?", tanya Nasthura.

"Orang Quraisy dari Mekah,” Maisarah menjawab. "Tidak seorang pun berteduh di bawah pohon itu, melainkan dia seorang nabi," kata Nasthura. Maisarah tercengang mendengarnya. Belum habis rasa terkejut Maisarah, Nasthura kembali mengulanginya. "Ia adalah nabi terakhir." Perasaan Maisarah campur aduk: gembira, senang, terkejut, dan gelisah. Sebuah rahasia besar berada di genggamannya. Ia merasa beruntung dapat mendampingi seorang pemuda yang kelak akan menjadi nabi.
Di siang hari, cuaca panas seperti memanggang rombongan, kulit kepala mereka terasa terbakar, kulit tubuh bercucuran keringat, mereka tidak kuasa menahan panggangan matahari. Saat itulah Maisarah menyaksikan mukjizat.

Segumpal awan terus menaungi Muhammad dan rombongan, kemanapun mereka bergerak. Awan itu terus berarak meneduhi Muhammad sepanjang perjalanan, seolah diperintahkan untuk mengikutinya. Hanya Maisarah yang melihat keajaiban itu. Para musafir lainya tidak ada yang tahu. Pemandangan menakjubkan itu membuat Maisarah kian yakin dengan apa yang diucapkan pendeta Nasthura bahwa Muhammad adalah nabi terakhir.

Setibanya di Makkah, Muhammad langsung menuju kediaman Khadijah. Sesampainya di sana, ia menyetorkan modal dan keuntungan kepada Khadijah. Kemudian Muhammad menjual barang dagangan yang beliau beli di Syam. Muhammad mendapat keuntungan lebih atas perniagaan itu. Khadijah terlihat gembira dengan usaha Muhammad muda. Tidak sia-sia ia memberikan kepercayaan kepada Muhammad. 
Muhammad segera kembali ke rumahnya. Saat itulah Maisarah menuturkan kepada Khadijah beragam peristiwa yang terjadi saat mendampingi Muhammad berdagang. Maisarah mengisahkan pertemuannya dengan seorang pendeta dan apa yang dikatakan sang pendeta tentang Muhammad. Dia menuturkan pula tentang awan yang menaungi Muhammad selama dalam perjalanan. Khadijah mendengarkan dengan penuh perhatian seolah tak ingin melewatkan sedikitpun informasi tentang Muhammad.

Dalam riwayat lain Maisarah orang kepercayaan menceritakan pada khadijah tentang kejujuran dan keikhlasan Muhammmad. Khadijah memperoleh keuntungan yang berlimpah dari perjalanan dagang tersebut, sehingga dia pun melipatgandakan imbalan bagi Muhammad dari biasanya. ${ }^{9}$

Semua yang dikisahkan Maisarah membuat khadijah kian kagum kepada Muhammad. Hal yang sebelumnya tidak pernah terpikirkan olehnya, selama ini banyak lelaki yang ingin menikahinya, tetapi ia selalu menolaknya. Keinginan untuk menjadi istri Muhammad kemudian ia sampaikan kepada temannya, Nafisah binti Munayah, Khadijah meminta Nafisah menemui Muhammad.

Saat bertemu Muhammad, Nafisah mengajukan sebuah pertanyaan, "mengapa engkau tidak menikah?”.

Muhammad tidak mengira akan ditanya seperti itu, saat Muhammad muda terdiam, Nafisah melanjutkan perkataannya, "kalau ada seorang wanita jujur dan terhormat dan ia menerimamu apa adanya, apa pendapatmu?"

“Siapa dia?" Tanya Muhammad penasaran, "Khadijah, wanita paling istimewa di Makkah, “jawab Nafisah. Ia kemudian menyampaikan pesan Khadijah.

"Wahai saudara sepupuku, aku menyukai dirimu sebab kesederhanaan dan kedekatanmu dengan kaummu, keteguhanmu menunaikan amanah, akhlak muliamu, dan kejujuranmu dalam berucap", kata Nafisah, menirukan apa yang diucapkan Khadijah. Awalnya Muhammad muda terkejut, ia tak menduga dirinya dilamar Khadijah, seorang wanita Quraisy yang amat dihormati dan wanita kaya raya. Setiap pria

\footnotetext{
${ }^{9}$ Musthafa As-Siba'i. (2011). Sirah Nabawiyah (Pelajaran dari kehidupan Nabi). hlm.23.
} 
Quraisy amat mendambakan Khadijah menjadi istrinya, andai mereka mampu.

Setelah cukup lama merenung, Muhammad menyetujui permintaan Khadijah, lalu ia menceritakan hal tersebut kepada pamannya, tanpa menunggu lama, para paman Muhammad mendatangi paman Khadijah untuk melamar.

Hari pernikahan disepakati, Muhammad muda mendatangi kediaman Khadijah didampingi keluarga besarnya. Abu Thalib, pamannya terlihat gembira, pada satu kesempatan, ia maju dan berdiri di depan para undangan.

"Muhammad berbeda dengan pemuda yang lain, tidak ada yang secerdas, sebaik dan sesopan Muhammad, kami ingin menikahkan putri kalian dengan putra kami, untuk itu, kami memberikan mahar 20 ekor unta", kata Abu Thalib.

Dalam riwayat lain, Ibnu Ishaq menuturkan tentang Khadijah binti Khuwailid adalah seorang wanita pedagang, terpandang, dan kaya raya. Dia biasa menyuruh orang-orang menjalankan barang dagangannya, dengan membagi sebagian

10 Ibnu Hisyam. (1337 H). Sirah Nabawiyah. Qalbu Jaziratil-Arab, Muhadharat Tarikhil-Umam hasilnya kepada mereka. Sementara orangorang Quraisy memiliki hobi berdagang. Tatkala Khadijah mendengar kabar tentang kejujuran perkataan beliau, kredibilitas dan memuliakan akhlak beliau, maka dia pun mengirimkan utusan dan menawarkan kepada beliau agar berangkat ke negeri Syam untuk menjalankan barang dagangannya. Dia siap memberikan imbalan jauh lebih banyak dari imbalan yang pernah dia berikan kepada pedagang yang lain. Beliau harus pergi bersama seorang pembantu yang bernama Maisarah. Beliau menerima tawaran ini, maka beliau berangkat ke negri Syam untuk berdagang dengan disertai Maisarah. ${ }^{10}$

\section{Jenis Perdagangan (Bisnis) yang Dilakukan Nabi Muhammad S.A.W.}

Bentuk dan jenis perdagangan bangsa Arab jahiliah sangat variatif, diantaranya, para pemilik modal dapat terlibat langsung dalam mengelola perdagangan, atau hanya sebagai penanam modal (investor). Janda kaya atau anak-anak yatim yang memiliki peninggalan harta benda, misalnya, dapat menginvestasikan modalnya kepada orangorang yang pandai dalam berdagang dan

Al-Islamiyah. Syaikh Syafiyyurrahman AlMubarakfuri. (2017). Sirah Nabawiyah. hlm. 56. 
dianggap bisa dipercaya. Bentuk ini dikenal dengan nama muqaradah atau mudharabah.

Mudharabah adalah satu bentuk kerjasama bisnis antara dua belah pihak atau lebih, dimana pihak pertama menyediakan dana (sahib al-mal) dan pihak kedua memberikan keahlian dan kemampuan manajemen (mudharib). Kedua pihak sepakat untuk berkongsi untung dan rugi dalam satu proyek atau unit usaha. Jika terdapat keuntungan, keuntungan itu dibagi sesuai nisbah (ratio) yang telah disepakati. Manakala terjadi kerugian, kerugian itu akan ditanggung penyandang dana, selama tidak timbul dari kecurangan dan/atau kelalaian mudharib. Jika mudarib melakukan manipulasi yang berakibat pada kerugian, kerugian sepenuhnya ditanggung mudharib.

Dalam perkembangannya, mudharabah memiliki berbagai corak, termasuk di dalamnya mudharabah mutlaqoh (umum) dan mudarabah muqayyadah (dibatasi dengan ketentuan-ketentuan bisnis tertentu). Bentuk perdagangan inilah yang pernah dipraktikkan oleh Nabi Muhammad ketika kerjasama dengan investor Khadijah binti Khuwailid. Penduduk Hijaz menyebut kerjasama itu dengan istilah mudharabah, sementara penduduk Irak menamainya dengan istilah muqaradah.

Bangsa Quraisy pra-Islam hidup pada masa jahiliyah yang berarti "masa kebodohan" kehidupan bangsa Arab pada saat itu sarat dengan prilaku bodoh yang merugikan diri sendiri, keluarga dan masyarakat. Mereka senang melakukan praktik bisnis ribawi, memperjualbelikan manusia (perbudakan), berjudi, meyakini takhayul, minum-minuman keras, berzina, merampok suku lain, mengubur anak perempuan hidup-hidup, dan lain-lain.

Di tengah-tengah kejahiliahan itu, Muhammad sering merenung dan menyendiri, memikirkan kondisi yang terjadi di masyarakat. Tatkala Allah mengangkat beliau sebagai nabi dan Rasul, beliau memperkenalkan sekaligus menyeru umatnya untuk meninggalkan berbagai perilaku dan tradisi jahiliyah, termasuk kejahiliyahan dalam berniaga dan berbisnis.

Ajaran yang disampaikan Nabi Muhammad sangat apresiatif terhadap perdagangan yang praktiknya dilandasi etika bisnis Islami. Sedangkan perdagangan yang mengandung unsur ribawi, ebagaimana biasa dilakukan bang Arab jahiliyah, termasuk kategori yang diharamkan. Allah S.W.T. 
menghilangkan keberkahan pada harta dari riba, dalam Surat Al-Baqarah Allah S.W.T. sebagiberikut:

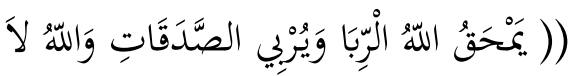

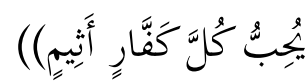

"Allah memusnahkan riba dan menyuburkan sedekah. Dan Allah tidak menyukai setiap orang yang tetap dalam kekafiran, dan selalu berbuat dosa." (Q.S. Al-Baqarah [2]: 276)

Maksudnya yamhaqullah ar-riba yaitu Allah S.W.T. hilangkan keberkahan harta yang tercampuri dengan riba, meskipun harta yang dihasilkannya melimpah, tidak ada sedikitpun kebaikan dari hasil jual beli dengan cara riba, orang yang melakukan akad jual beli dengan cara riba akan merasa cemas, gelisah, dan lelah di dunia dan di akhirat. ${ }^{11}$

Allah S.W.T. juga mengatakan perang bagi pelaku riba, sebagaimana firman-Nya:

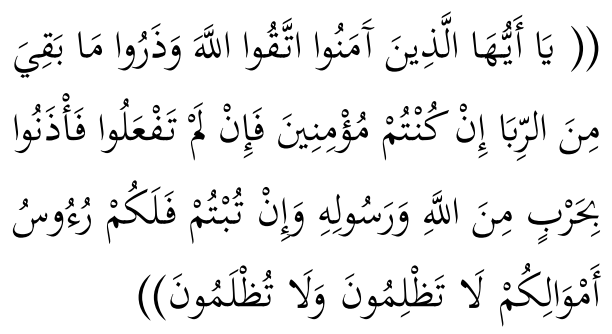

${ }^{11}$ Shalih ibn Fauzan ibn Abdullah Al-Fauzan. (1423). Al-Mulakhkhash Al-Fikhiy. Riadh: Dar AlAashimah. hlm. 33.
"Hai orang-orang beriman, bertakwalah pada Allah dan tinggalkan sisa riba jika kamu orang-orang yang beriman. Maka jika kamu tidak melaksanakan (apa yang diperintahkan ini) maka ketahuilah, bahwa akan terjadi perang dahsyat dari Allah dan RosulNya dan jika kamu bertaubat maka bagi kamu pokok harta kamu, kamu tidak dianiaya dan tidak (pula) dianiaya". (Q.S. Al-

\section{Baqarah [2]: 278-279)}

Rasulullah Melaknat pelaku riba sebagaiman hadits Dari Jabir, Nabi S.A.W. bersabda: ${ }^{12}$

لَعَنَ رَسُولُ اللَّهِ صلى الله عليه وسلم آكِلَ

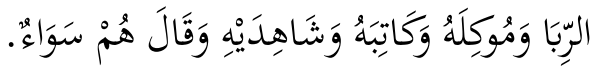
"Rasulullah shallallahu 'alaihi wa sallam melaknat pemakan riba (rentenir), penyetor riba (nasabah yang meminjam), penulis transaksi riba (sekretaris) dan dua saksi yang menyaksikan transaksi riba." Kata beliau, "Semuanya sama dalam dosa." (HR. Muslim)

12 Shalih ibn Fauzan ibn Abdullah Al-Fauzan. (1423). hlm. 34. 
Dan berniaga dengan cara riba juga tidak dapat berdiri pada hari kiamat kecuali seperti berdirinya orang yang kemasukan setan.

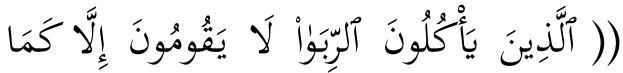

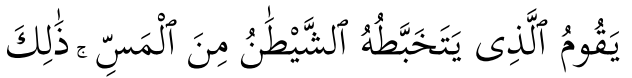

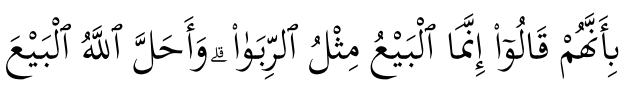

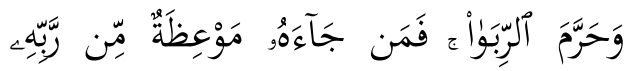

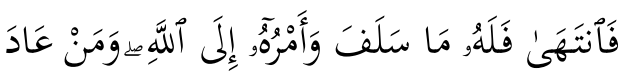

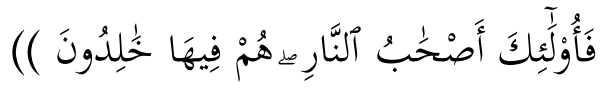

$$
\begin{aligned}
& \text { "Orang-orang yang (makan) riba } \\
& \text { tidak dapat berdiri melainkan seperti } \\
& \text { berdirinya orang-orang yang } \\
& \text { kemasukan setan lantaran (tekanan) } \\
& \text { penyakit gila. Keadaan mereka yang } \\
& \text { demikian itu lantaran mereka } \\
& \text { berkata bahwa sesungguhnya jual } \\
& \text { beli itu sama dengan riba, padahal } \\
& \text { Allah telah meghalalkan jual beli } \\
& \text { dan mengharamkan riba. Orang- } \\
& \text { orang yang telah sampai kepadanya } \\
& \text { larangan dari tuhannya, lalu } \\
& \text { berhenti (dari mengambil riba), } \\
& \text { maka baginya yang telah diambil } \\
& \text { dahulu, dan urusannya (terserah) } \\
& \text { kepada Allah. Orang yang }
\end{aligned}
$$

13 Shalih ibn Fauzan ibn Abdullah Al-Fauzan. (1423). hlm. 9. mengulangi (mengambil riba), maka orang itu adalah penghuni neraka, mereka kekal di dalamnya." (Q.S.

Al-Baqarah [2]: 275).

Tidak itu saja, Nabi Muhammad pun memperkenalkan syarat-syarat jual beli, di antarany syarat-syaratnya: ${ }^{13}$

- An taradhin (saling merelakan satu sama lain) tidakada paksaan antara pembeli dan penjual

- Berakal, mukallaf, dan tidak dibenarkan anak-anak

- Adanya barang yang dijual belikan atau memiliki barang yang dijual secara penuh, Rasulullah bersabda:

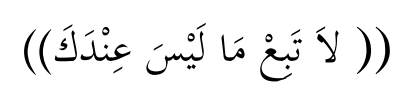

"Janganlah engkau menjual barang yang bukan milikmu." (HR.

\section{Abu Daud, An-Nasai, dan At- Tirmidzi)}

Rasulullah S.A.W. melarang transaksi jual-beli dengan unsur tipu daya atau kecurangan yang acap kali ditempuh para pedagang bangsa Arab Jahiliyah. Nabi Muhammmad S.A.W. menjelaskan, jual beli semacam itu tidak sah karena merugikan 
pihak lain. Beliau menyampaikan kepada kaumnya bahwa dalam Islam terdapat kerangka dasar etika yang harus diterapkan saat transaksi jual beli. ${ }^{14}$

\section{KESIMPULAN}

Perjalanan bisnis Nabi Muhammad Salallahu alaihi wasallam dimulai saat beliau berusia 12 tahun, beliau telah dikenalkan dunia bisnis oleh pamannya yaitu Abu Thalib dengan melakukan perjalanan bisnis ke wilayah Syam (Syria), dalam perkembangan selanjutnya, beliau terus menekuni profesi sebagai pebisnis sampai dewasa, banyak dari kalangan kaumnya di Mekkah mempercayakan pengelolaaan perdagangannya kepada Muhammad Salallahu alaihi wasallam, sampai dijuluki Al-Amin (terpercaya) beliau menjadi investment manager. Saat usia 25 tahun beliau mengelola perdagangan dengan Khadijah dan melakukan perjalanan bisnisnya sebagai mitra, dan selanjutnya setelah menikah beliau bersama menjalankan bisnisnya sebagai business owner. Menginjak usia 30-40 sebelum masa

${ }^{14}$ M. Syafi'i Antonio. (2010). Muhammad The Super Leader Super Manger. Tazkia Publishing. hlm. 8-9. kenabian, Muhammad Salallahu alaihi wasallam menjadi seorang Investor dan mulai memiliki banyak waktu, pada saat itu beliau sudah mencapai apa yang disebut sebagai "Financial Freedom" kebebasan uang dan waktu.

\section{DAFTAR PUSTAKA}

Al-Fauzan, S. (1423). Al-Mulakhkhash AlFikhiy. Riadh: Dar Al-Aashimah.

Al-Mubarak Furi, S. (2017). Sirah Nabawiyah. Jakarta: Pustaka Al Kautsar.

Al-Ghazali Muhammad. (1391 H). FiqhusSirah. Mesir: Darul KitabAl-Arabi.

Al-Mubarakfuri, S. (2017). Arrahiiqul makhtum sirah nabawiyah. Jakarta: Pustaka Al Kautsar.

At-Tamimi, M.W. (1375). Mukhtashar Siratir-Rasul Shahih Al-Bukhari, Kitabut-Ta 'bir, Awwalu Ma Budi'a Bihi Rasulillahminal wahyi Ar-Ru'ya AshShalihah.

Antonio, MS. (2010). Muhammad The super leader super manger. Tazkia Publishing.

Antonio, M.S (2010). Ensiklopedia leadership dan manajemen Muhammad, "The super leader super manager". Tazkia publishing. 
Fachrudin, F. (2013). "Fikih Bekerja." AlMahslahah: Jurnal Hukum Islam dan Pranata Sosial Islam, 1(01).

Hisyam, I. (1337 H). Sirah Nabawiyah. Qalbu Jaziratil-Arab, Muhadharat Tarikhil-Umam Al-Islamiyah.

Haekal, M. (2011). Sejarah hidup Muhammad.

Maya, R. (2015). "Perspektif Islam Tentang Konsep Life Skill." Edukasi Islami: Jurnal Pendidikan Islam, 04(07).

Muhammad, A. (1387 H). Mukhtashar Siratir-Rasul Sallahu Alaihi wa Sallam. Mesir.

Musthafa As-Siba'i. (2011). Sirah Nabawiyah (Pelajaran dari kehidupan Nabi).

Sayid, Q. (1382 H). fi Zhilalil Qur'an. Beirut; Darul Ihya' it Turats Al-Arabi.

(1999 H). Al-Quran dan Terjemahnya, Khadim Al-Haramain Asy Syarifain Raja Fahd ibn Abd Al-Aziz Al Sa’ud. 